\title{
EXTRACTION AND CHARACTERISATION OF CELLULOSE FROM THE RESIDUE OF OIL PALM EMPTY FRUIT BUNCH-XYLAN EXTRACTION
}

\author{
NOORSHAMSIANA, A $\mathbf{W}^{*}$; NOR FAIZAH, $\mathbf{J}^{*}$; KAMARUDIN, $\mathrm{H}^{*}$; \\ NUR ELIYANTI, A O*; FATIHA, I* and ASTIMAR, A A*
}

\begin{abstract}
Cellulosic solid residual, which is the by-product of oil palm empty fruit bunch (OPEFB)-xylan extraction process, was evaluated in terms of cellulose recovery by eco-friendly approach. The OPEFB-fibre was initially treated with alkaline for xylan extraction. The resulting solid residue was dried before treated with mild concentration of bleaching agents of $20 \%(v / v)$ formic acid and $5 \%(v / v)$ hydrogen peroxide at $85^{\circ} \mathrm{C}$ for the extraction of cellulose. The $\alpha$-cellulose content of $84.16 \pm 0.4 \%$ was achieved. Fourier transform infrared spectroscopy (FTIR) analysis showed that the products obtained have the standard cellulose structure and functional group. The crystalline nature of the extracted cellulose, as proven by $X$-ray diffractometer (XRD) has crystallinity index and crystalline size of $54.4 \%$ and $5.5 \mathrm{~nm}$, respectively, whereas the thermogravimetric analysis (TGA) indicates the sample purity in terms of thermal stability at $370^{\circ} \mathrm{C}$ by comparing the results to commercially available cellulose. Meanwhile, scanning electron microscope (SEM) observation showed that the extracted cellulose morphology is in the form of separated fibrils. In terms of impurities, trace elemental analysis showed the presence of phosphorus $(P)$ as the major element but the quantity of fluorine (F), chlorine (Cl), bromine (Br), iodine (I) and sulphur (S) detected on the cellulose was insignificant.
\end{abstract}

Keywords: cellulose, eco-friendly extraction, oil palm empty fruit bunch, xylan extraction residue.

Received: 4 November 2019; Accepted: 13 February 2020; Published online: 2 September 2020

\section{INTRODUCTION}

Oil palm empty fruit bunch (OPEFB) is the most abundant biomass generated by the mills after extracting the oil from fresh fruit bunch (FFB). In 2018, 485 palm oil mills in Malaysia processed 118.9 million tonnes of FFB generating approximately 9.16 million tonnes (dry weight) of OPEFB (Kushairi et al., 2019). The abundant quantity of OPEFB generated in the oil palm mills provides huge resources for conversion into value-added products, as the OPEFB is inexhaustible, renewable,

Malaysian Palm Oil Board,

6 Persiaran Institusi, Bandar Baru Bangi,

43000 Kajang, Selangor, Malaysia.

E-mail: noorsham@mpob.gov.my biodegradable, recyclable and a derivatisable biopolymer. Lignocellulosic material (LCM) in biomass waste composed of about $37.1 \%$ cellulose, $39.9 \%$ hemicellulose, $18.6 \%$ lignin and $3.1 \%$ extractives (Megashah et al., 2018). Each of these lignocellulosic components can be extracted and exploited for the production of fine chemicals, especially from cellulose and hemicellulose.

In previous study, a method was developed to produce the xylooligosaccharides (XOS) from OPEFB fibre at laboratory scale (Noorshamsiana et al., 2015). In this method, hemicellulose was extracted from OPEFB-fibre using alkaline solution and precipitated into xylan as starting material for the production of XOS using enzymatic method. $\mathrm{XOS}$ is one of the most promising prebiotic products which is extensively studied and proven to 
stimulate microflora growth in the gastrointestinal tract (Manderson et al., 2005; Parajó et al., 2004). In fact, XOS gains much attention as it possesses many health benefits, particularly in prebiotic activities besides being food additive and health products (Gupta et al., 2012; Seema and Arun, 2011; Moure et al., 2006; Alonso et al., 2003). The solid residue generated from xylan extraction using alkaline solution has yet to be explored. The solid residue is in fact a LCM which consists of cellulose, lignin, as well as some traces of hemicellulose. Cellulose is another value-added product from natural fibre and it is useful in food and pharmaceutical applications. Cellulose is the most abundant polysaccharide, comprising about $44 \%-64 \%$ of plant materials (Mansor et al., 2019; Nazir et al., 2013; Dhillon et al., 2013; Nawirska and Kwasniewska, 2005; Wanrosli et al., 2004; McKendry, 2002) and OPEFB-fibre contains about $40 \%-65 \%$ of cellulose (Megashah et al., 2018; Zakaria et al., 2015; Adela et al., 2014; Chang et al., 2014; Ching and Ng, 2014; Khalil et al., 2008; Law et al., 2007). Cellulose is a natural long-chain polymer that indirectly contributes to the human food cycle. This polymer has versatile uses in many industries, such as veterinary food, pulp and paper, and fibre for clothing. In addition, cellulose has a semi-synthetic derivative which is extensively used in pharmaceutical and cosmetic industries.

Cellulose can be extracted from natural fibres via chemical and mechanical methods. Acidified sodium chlorite $\left(\mathrm{NaClO}_{2}+\mathrm{H}_{3} \mathrm{O}^{+}\right)$is commonly used as the standard reagent for cellulose delignification and extraction from wood materials (SzymańskaChargot et al., 2017; Hook et al., 2015; Brendel et al., 2000; Leavitt and Danzer, 1993; Loader et al., 1997; Wise et al., 1946). Chlorite $\left(\mathrm{ClO}_{2}-\right)$ produces chlorine radical which is reactive and fragments the LCM into highly toxic organochlorine. The cellulose extraction from OPEFB-fibre involves pretreatment with toluene/methanol $(2: 1, \mathrm{v} / \mathrm{v}$ ) (Sun et al., 1999) and ethanol/benzene (1:2) (Fahma et al., 2010), with further delignification using chlorite to prepare microcrystalline cellulose (Rosnah et al., 2009). However, the existing procedures produce low yields as well as neither environment-friendly nor energy efficient. Therefore, more focus should be placed on eco-friendly methods in cellulose extraction by utilising green treatment that reduces or eliminates hazardous chemicals, using safer solvent and safer reaction conditions. Organic acids such as acetic acid and formic acid are ecofriendly reagents, less corrosive and effective for the pre-treatment of lignocellulosic biomass, and they provide a more stable medium in the aqueous phase for monosaccharide than sulphuric acid (Marzialetti et al., 2011). A mixture of hexane/ ethanol and water is used to remove wax from the rice husk, followed by autoclaving and ultrasound treatments to delignify and purify cellulose using hydrogen peroxide and acetic acid (Simone et al., 2012). The cellulose extraction from OPEFB using hydrogen peroxide with ultrasound-assisted alkali extraction produced cellulose with 49\% yield (Nazir et al., 2012). The use of low concentrations of formic acid $(20 \%, \mathrm{v} / \mathrm{v})$ and $30 \%$ hydrogen peroxide $(10 \%, \mathrm{v} / \mathrm{v})$ at $85^{\circ} \mathrm{C}$ to extract cellulose from OPEFB produced $64 \%(\mathrm{w} / \mathrm{w})$ cellulose, which is the highest ever reported (Nazir et al., 2013). The development of a novel process that uses ionic liquid followed by alkaline method to extract cellulose from OPEFB fibre resulted in $93 \% \alpha$-cellulose recovery (Norzita and Lani, 2014). From the literature, most studies only focused on cellulose extraction from raw OPEFB fibre. This research focused on cellulose recovery from the by-product of hemicellulose extraction from OPEFB.

This study aims to extract cellulose from the by-product of hemicellulose extraction using green method in order to solve the disposal problem of the process as well as to create another value added products from the OPEFB fibre. Thus, the use of bleaching agents in mild concentration to recover cellulose from the residue of OPEFB-xylan extraction is out of concern for environmental protection. The characterisation of the product obtained was carried out by Fourier transform infrared spectroscopy (FTIR), X-ray diffractometry (XRD), thermogravimetric (TG), elemental analyser and scanning electron microscope (SEM).

\section{MATERIALS AND METHODS}

\section{Materials}

OPEFB-fibres were obtained from Biomass Plant, Biomass Technology Unit, MPOB-UKM in Bangi, Selangor, Malaysia. The treated and dried OPEFB fibre was ground and stored in the cold room prior to use. The hemicellulose extracted from OPEFB fibres using alkaline solution and precipitated into xylan was the starting material for the production of XOS using enzymatic method (Noorshamsiana et al., 2015). The resulting solid residue from the xylan extraction process was further treated for cellulose recovery. The cellulose standard derived from spruce with $>99 \%$ purity (FLUKA) was used as reference. All chemicals and solvents used are of reagent grade and were used as received.

\section{Cellulose Recovery from the Solid Residue of Xylan Extraction}

Cellulose extraction was adapted and modified from the method developed for OPEFB fibres (Nazir et al., 2013). The solid residue was dried in the oven at $50^{\circ} \mathrm{C}$ to a constant weight before extracting. Two grams of solid residue were soaked in a mixture of $100 \mathrm{ml} \mathrm{20 \%} \mathrm{formic} \mathrm{acid}\left(\mathrm{CH}_{2} \mathrm{O}_{2}\right)$ and $100 \mathrm{ml} 5 \%$ 
hydrogen peroxide $\left(\mathrm{H}_{2} \mathrm{O}_{2}\right)$. The mixture was then placed in the shaking water bath (WiseBath, Daihan Scientific; 45 litre) at $85^{\circ} \mathrm{C}$ for $2 \mathrm{hr}$. After hydrolysis, the samples were filtered with grade 4 filter paper (Whatman, England) and the supernatant washed with $10 \% \quad \mathrm{CH}_{2} \mathrm{O}_{2}$ before being washed with distilled water several times. The supernatant was resuspended with $10 \% \mathrm{H}_{2} \mathrm{O}_{2}$ and $10 \% \mathrm{NaOH}$ at $\mathrm{pH}$ 11 and $60^{\circ} \mathrm{C}$ for $90 \mathrm{~min}$. The product obtained was then filtered, washed with distilled water and dried in oven at $60^{\circ} \mathrm{C}$ before being characterised. The $\alpha$-cellulose content was determined by TAPPI T203 method.

\section{FTIR}

The infrared spectrum of the extracted cellulose was recorded using Perkin-Elmer Spectrum Frontier FTIR Spectrometer with wavelength in the range of 4000-650 $\mathrm{cm}^{-1}$. The spectrum was compared with standard cellulose.

\section{XRD}

The phase behaviour of standard cellulose and extracted cellulose was elucidated by using an X-ray diffractometer (D8-Advance Bruker-AXS Germany). The peak measurement was conducted by taking $2 \ominus$ value between $5^{\circ}$ and $60^{\circ}$ with $0.04^{\circ}$ $\min ^{-1}$ step size. The crystallinity index $\left(C_{I r}\right)$ was calculated based on Segal method (Segal et al., 1959) as follows:

$$
C_{I r}=\frac{I_{002}-I_{a m}}{I_{002}} \times 100 \%
$$

where $I_{002}$ is the maximum peak intensity of crystalline fractions located at $2 \Theta=22.0^{\circ}-22.5^{\circ}$, whereas $I_{a m}$ is the low peak intensity in the amorphous region at $2 \Theta=16^{\circ}$, which corresponds to the crystallographic plane.

Crystallite size $(\varepsilon)$ is used to indicate the quality of the crystals. It was determined using the Scherrer's equation (Patterson, 1939) as follows:

$$
\varepsilon=\frac{k \lambda}{\beta \cos \theta}
$$

where $k$ is the constant of $0.91, \lambda$ is the $\mathrm{X}$-ray wavelength, $\beta$ is the full width at half maximum (FWHM) peak intensity and $\Theta$ is the Bragg's angle.

\section{TGA}

TGA of the standard cellulose and extracted cellulose were performed using a Perkin Elmer Pyris 1 thermogravimetric analyser. About $10 \mathrm{mg}$ to
$20 \mathrm{mg}$ of each sample was analysed continuously from $30^{\circ} \mathrm{C}$ to $600^{\circ} \mathrm{C}$ at $20^{\circ} \mathrm{C} \mathrm{min}-1$ heating rate. The analyser was purged with nitrogen, followed by $20 \mathrm{ml}$ $\mathrm{min}^{-1}$ oxygen flow to prevent any thermo-oxidative degradation.

\section{SEM}

Morphological studies of the extracted cellulose and standard cellulose were carried out with a SEM, Hitachi S-3400 N. A piece of dry sample was put on the SEM sample lens, then the lenses were placed in a vacuum chamber to avoid obstruction and contamination by other particles. The lenses helped to direct electrons towards the sample. The electron imprint was converted into three-dimensional image. Elemental analysis was performed using an energy-dispersive X-ray (EDX) coupled with SEM. When electron beam penetrated the sample, the produced X-ray was collected, analysed and detected by silicon drift detector (SDD) and the $\mathrm{X}$-ray map recorded.

\section{Elemental Composition Analysis}

The elements in the cellulose samples were analysed using CHN628 Series Elemental Determinator. The instrument is used to determine nitrogen, carbon/nitrogen, and carbon/hydrogen/ nitrogen composition in organic matrices by utilising combustion technique.

\section{Trace Element Content}

Cellulose samples were analysed for nitrogen, sulphur and halogen content using NSX-2100 Automatic Combustion Unit (Model AQF-2100 series).

\section{RESULTS AND DISCUSSION}

\section{Eco-friendly Extraction of Cellulose from the Solid Residue of OPEFB-xylan Extraction Process}

The solid residue generated from OPEFB-xylan extraction was treated with mild bleaching agents of $20 \%(\mathrm{v} / \mathrm{v})$ formic acid and 5\% (v/v) hydrogen peroxide at $85^{\circ} \mathrm{C}$, which yielded $82.69 \pm 3.9 \%$ cellulose with $\alpha$-cellulose content of $84.16 \pm 0.4 \%$. Formic acid was used to remove hemicellulose, leaving the solid residue to have lesser hemicellulose with high cellulose content (Goldmann et al., 2017; Li et al., 2015). Hence, more cellulose was obtained in the treated product. The major contributor of cellulose extraction was formic acid because it is very stable in aqueous medium (Nazir et al., 2013). A stable formic acid provided an alternative for the interaction and dissolution of non-crystalline 
part in cellulose. This helped to remove the non-lignin parts, hemicellulose and lignin by converting the hemicellulose into salt and lignin was converted to carboxylic acid. Hemicellulose and lignin were removed as water-soluble fraction while the insoluble crystalline cellulose was left suspended in the aqueous medium. A study by Li et al. (2015) found that formic acid is useful to remove hemicellulose, swells cellulose fibres, and releases cellulose nanocrystals (CNC). The findings showed that formic acid does increase the amount of hemicellulose extracted from biomass fibre, leaving behind the cellulose component. Furthermore, it was found that more cellulose can be recovered using formic acid at low temperature. The low temperature of $85^{\circ} \mathrm{C}$ favours hemicellulose hydrolysis rather than cellulose hydrolysis, resulting in more cellulose to be retained in the solid residue (Goldmann et al., 2017). It was also observed that cellulose recovery decreased with the increase in hydrogen peroxide concentration. This is due to the presence of $\mathrm{H}^{+}$ions that help to strengthen the microfibrillated lignin-cellulose structure, stiffness and stability (Lindman et al., 2010).

\section{Chemical Characterisation}

FTIR The extracted cellulose was analysed with FTIR and compared with standard cellulose (FLUKA), to determine the composition of functional group and confirm its chemical structure.

FTIR analysis showed that the spectrum of the OPEFB-based cellulose extracted using eco-friendly reagents was identical to that of standard cellulose, suggesting the presence of similar backbone and functional groups in both samples (Figure 1). The
$\mathrm{O}-\mathrm{H}$ bond which indicates the presence of $-\mathrm{OH}$ groups on the glucose unit is characterised by the broad band found in the range of 3200-3400 $\mathrm{cm}^{-1}$ (Norzita and Lani, 2014; Moran et al., 2008; Khalil et al., 2001). In this study, the $\mathrm{O}-\mathrm{H}$ bond of the extracted cellulose and standard cellulose was found at $3327.84 \mathrm{~cm}^{-1}$ and $3330.34 \mathrm{~cm}^{-1}$, respectively. The medium peak at $2891.61 \mathrm{~cm}^{-1}$ for extracted cellulose and $2893.33 \mathrm{~cm}^{-1}$ for standard cellulose reflects the $\mathrm{C}-\mathrm{H}$ bonds. Meanwhile, the peak at $1023.84 \mathrm{~cm}^{-1}$ for extracted cellulose and 1052.33 $\mathrm{cm}^{-1}$ for standard cellulose is assigned to the C-O-C linkage of the anhydrous repeating units. The peaks at $1735 \mathrm{~cm}^{-1}$ and $1375 \mathrm{~cm}^{-1}$, which represent wax and hemicellulose, respectively were not present in the extracted cellulose, indicating both components were removed during bleaching. From literature, the FTIR spectral peaks representing lignin at $1248 \mathrm{~cm}^{-1}$ and $1037 \mathrm{~cm}^{-1}$ were not observed in the extracted cellulose (Ching and Ng, 2014; Nazir et al., 2013; Simone et al., 2012). It was observed that the extracted cellulose had lower transmittance than standard cellulose. This may be due to the compound that exists in the extracted cellulose causes an increase in absorptivity, which leads to lower transmittance percentage. The extracted cellulose has similar structure and functional groups to that of standard cellulose, thus, confirming that the product was cellulose.

$X R D$. The XRD patterns of the extracted cellulose and standard cellulose are shown in Figure 2. The diffractogram (diffraction pattern) shows the presence of crystalline and amorphous fractions in both samples.

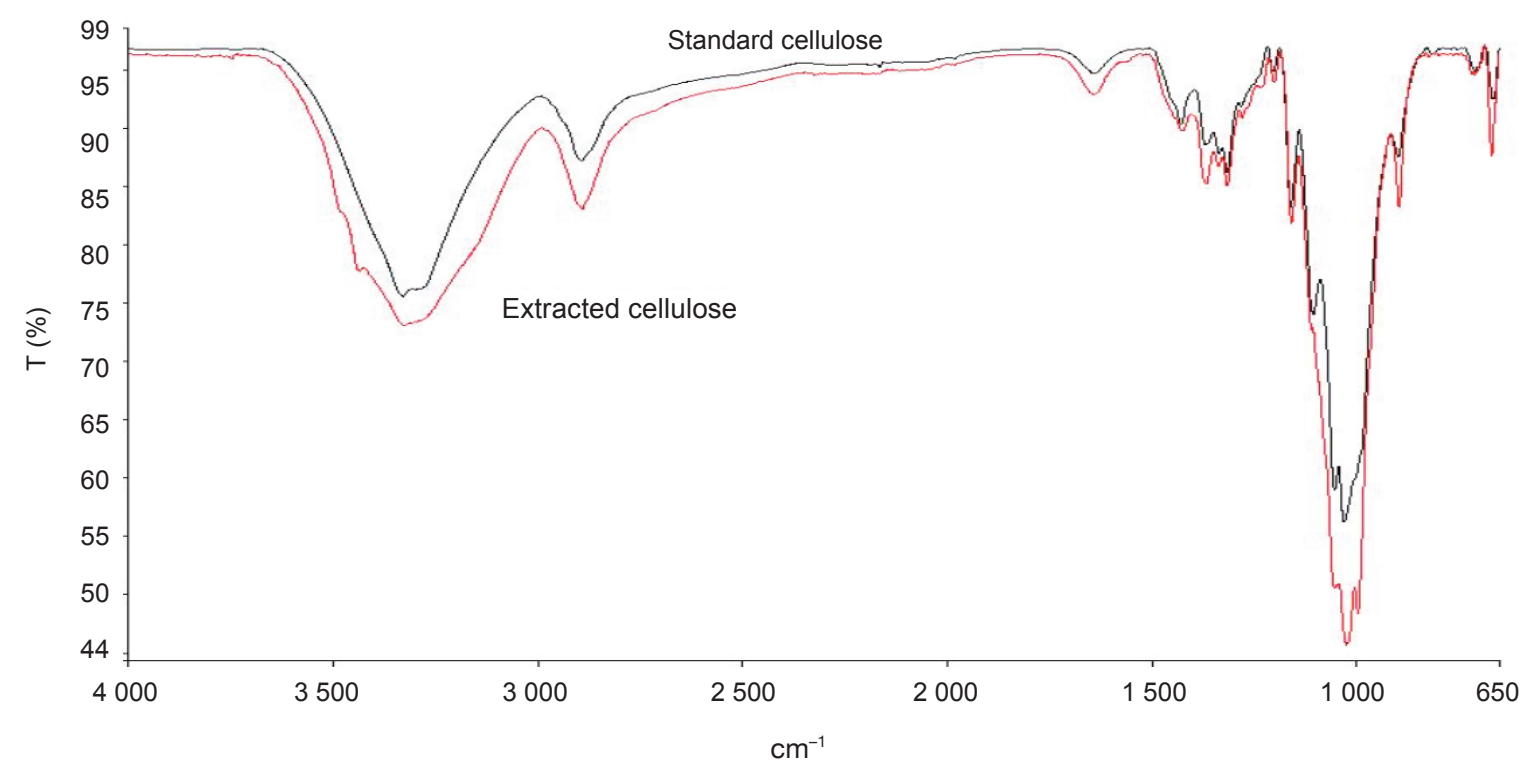

Figure 1. Fourier transform infrared spectroscopy (FTIR) spectra of extracted cellulose and standard cellulose. 


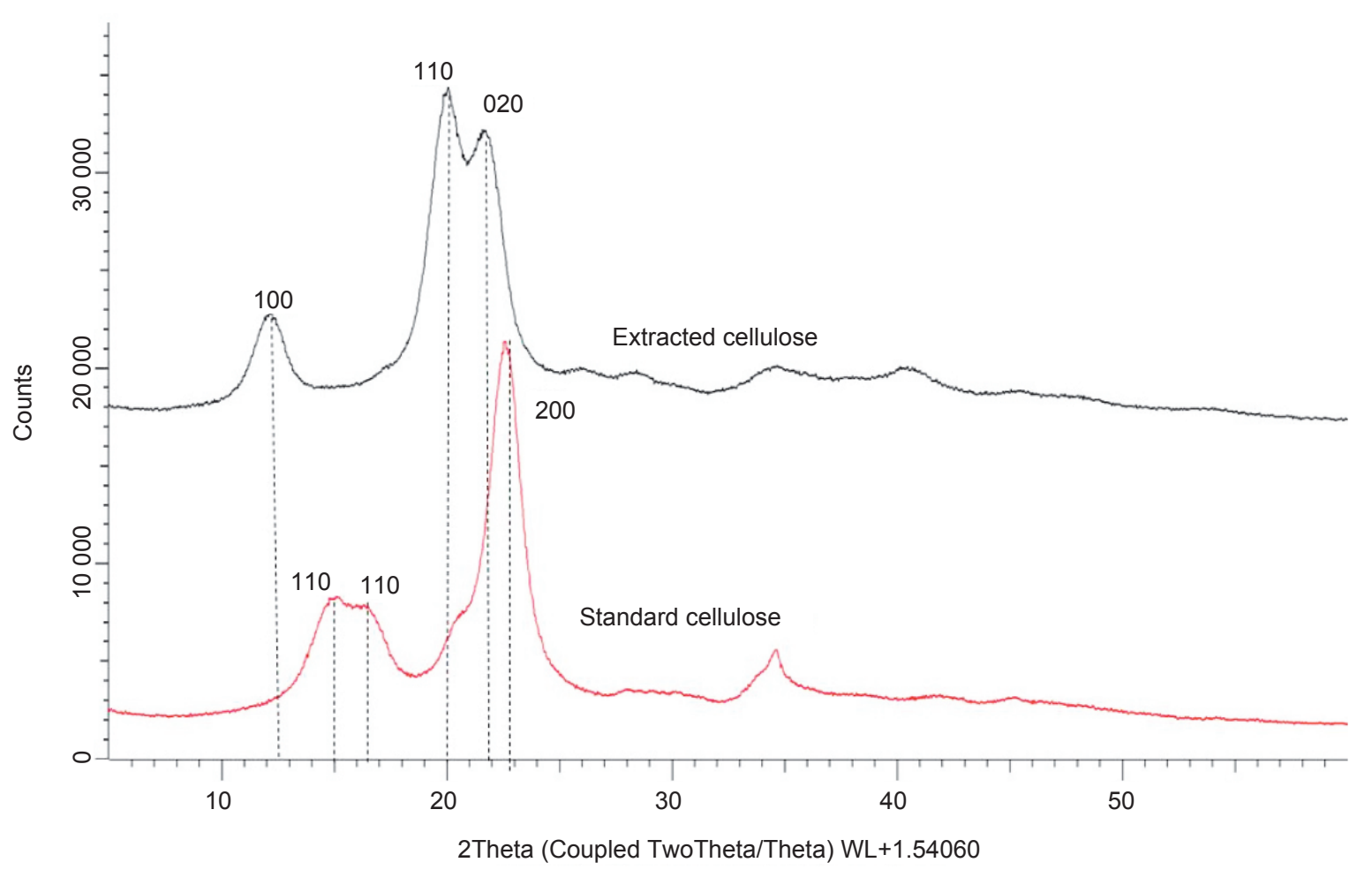

Figure 2. The X-ray diffraction (XRD) patterns of cellulose extracted from the residue of oil palm empty fruit bunch (OPEFB) xylan extraction and standard cellulose derived from spruce wood.

It is observed from Figure 2 that the standard cellulose has diffraction peaks around $2 \ominus=20^{\circ}-24^{\circ}$ while the extracted cellulose has diffraction peaks at $2 \ominus=18^{\circ}-24^{\circ}$. The standard cellulose $C_{I r}$ and $\varepsilon$ were $71.9 \%$ and $6.0 \mathrm{~nm}$, respectively, whereas for the extracted cellulose, they were $54.4 \%$ and 5.5 $\mathrm{nm}$, respectively. For comparison purposes, the crystallinity indexes of cellulose derived from native OPEFB fibres in the previous studies were 82.4\% (Megashah et al., 2018), 70\% (Nazir et al., 2013), 69\% (Jonoobi et al., 2011), 63\% (Norzita and Lani, 2014) and 55\% (Fahma et al., 2010). In general, the structures of the natural cellulose fibres are classified as type I, II, III and IV. It is observed that the standard cellulose is classified as cellulose type I as it has no doublet in the main peak of $2 \ominus=23^{\circ}$ (Norzita and Lani, 2014; Bhatnagar and Sain, 2005). Meanwhile, the cellulose derived from the solid residue of OPEFB-xylan extraction using mild bleaching agents is categorised as type II. This is based on the crystalline peak that appears as a doublet at $2 \ominus=20^{\circ}$ and $2 \ominus=22^{\circ}$, demonstrating the transformation of native cellulose from cellulose type I to cellulose type II.

TGA. The thermal behaviour and thermal stability of the samples obtained were studied using TGA to determine the changes in mass when temperature is increased over time.
TABLE 1. THERMAL ANALYSIS OF CELLULOSE

\begin{tabular}{lcc}
\hline Samples & $\begin{array}{c}\mathrm{T}_{50 \%} \\
\left({ }^{\circ} \mathrm{C}\right)\end{array}$ & $\begin{array}{c}\mathrm{T}_{\max } \\
\left({ }^{\circ} \mathrm{C}\right)\end{array}$ \\
\hline Extracted cellulose & 341.77 & 370.10 \\
Standard cellulose (FLUKA) & 358.04 & 396.47 \\
\hline
\end{tabular}

Figures $3 a$ and $3 b$ show the thermogram of the extracted cellulose and standard cellulose, respectively. It was observed that both cellulose samples exhibited single step degradation in the temperature range of $200^{\circ} \mathrm{C}-400^{\circ} \mathrm{C}$, indicating that the degradation was due to one main component. Weight loss was observed at around $100^{\circ} \mathrm{C}$, due to the loss of moisture in both samples. Looking at Table 1, it was observed that the standard cellulose was degraded by half at higher temperature and has higher maximum thermal decomposition compared to the extracted cellulose. The findings suggest that standard cellulose has better thermal stability than extracted cellulose. This is because the thermally unstable component in the extracted cellulose contains celluloses from different sources. The standard cellulose (FLUKA) (purity >99\%) is isolated from spruce wood, while the extracted cellulose is from the empty fruit bunch fibres. In addition, the cellulose extraction for these two samples are different, whereby, the standard cellulose is extracted using chemical method, whereas the cellulose in this study was extracted 
(a)

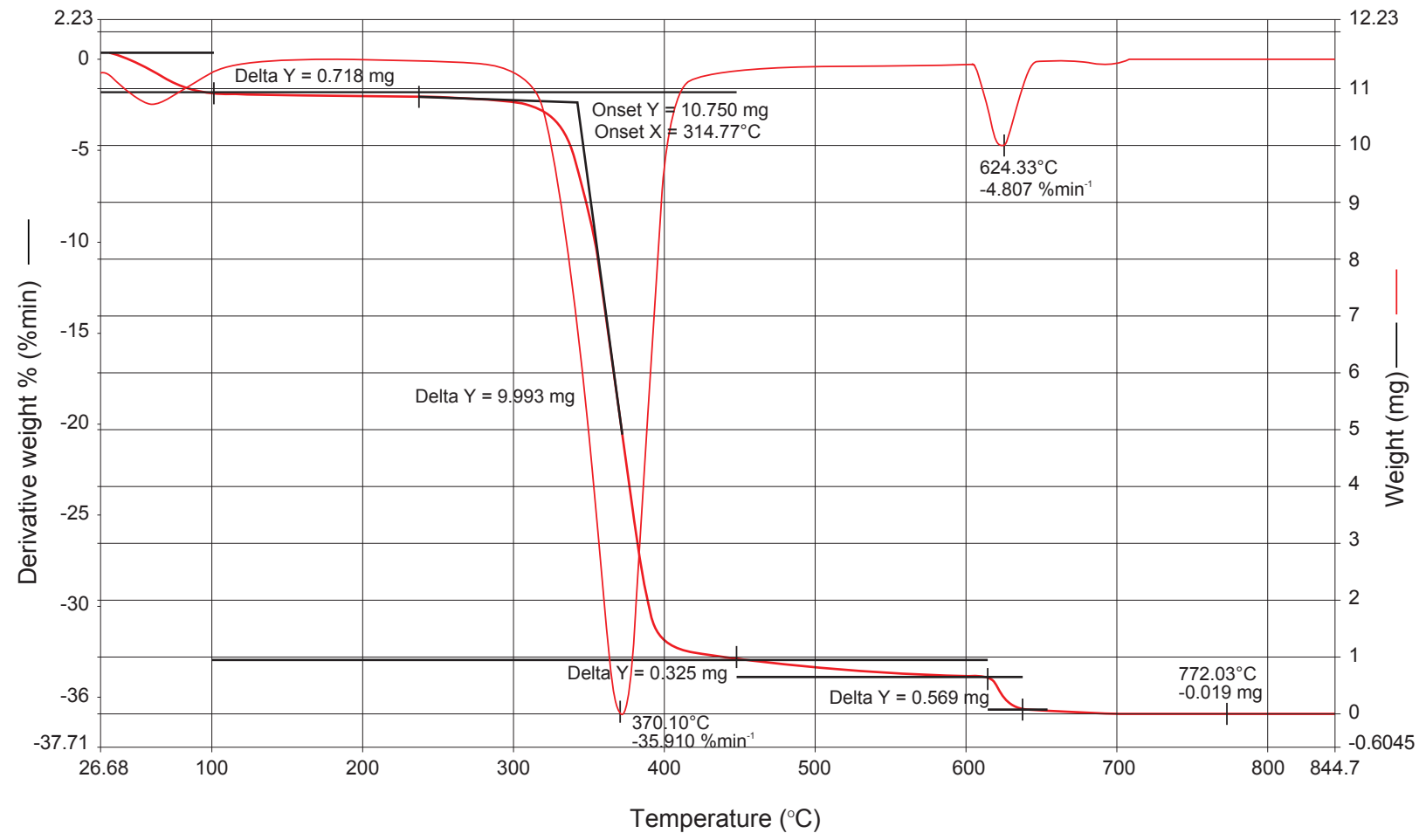

(b)

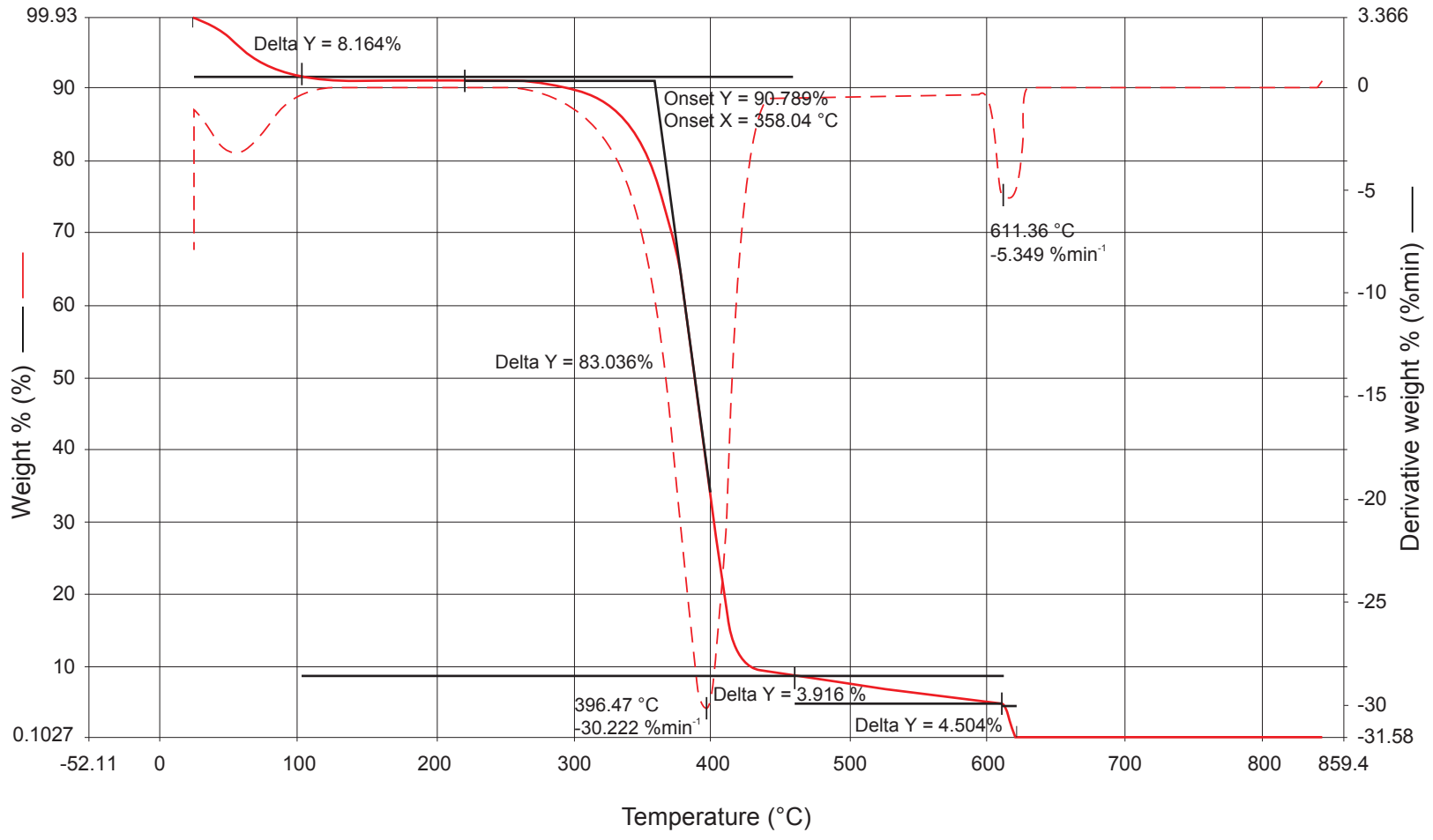

Figure 3. Thermogravimetric profile of (a) extracted cellulose (b) standard cellulose.

using eco-friendly reagents. Also, crystallinity is important in determining thermal stability. Lower crystalline region in the extracted cellulose results in lower thermal stability (Megashah et al., 2018; Nascimento et al., 2015; Poletto et al., 2014).
SEM. Surface morphology of the solid residue from the OPEFB-xylan extraction is depicted in Figure 4, whereas the surface morphology of the extracted cellulose and standard cellulose are depicted in Figures 5 and 6, respectively. 


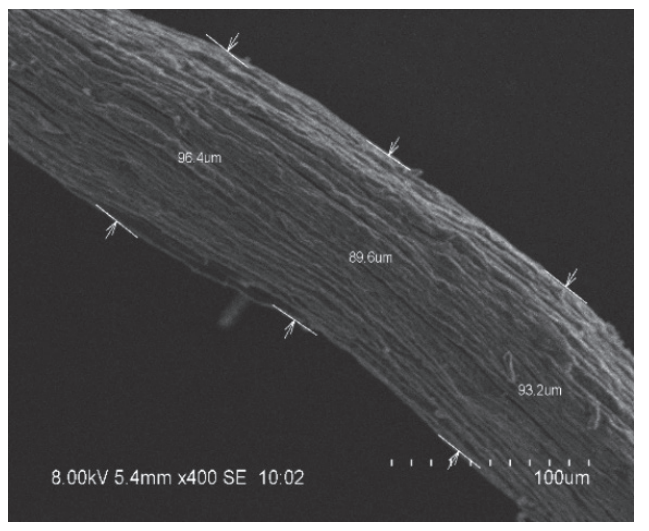

(a)

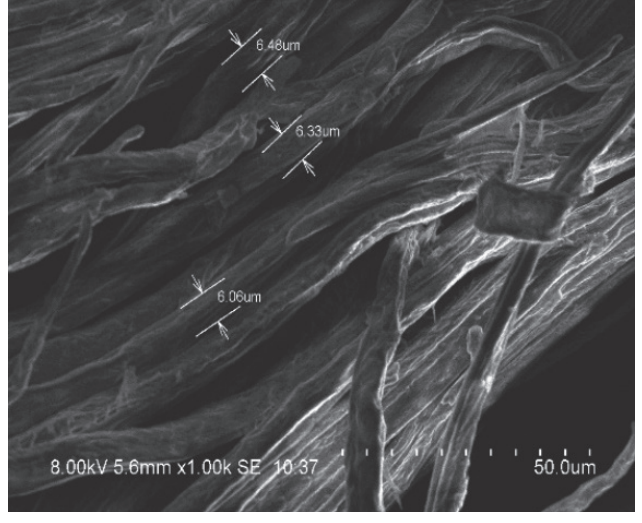

(b)

Figure 4. Scanning electron microscope (SEM) micrograph of the oil palm empty fruit bunch (OPEFB) xylan extraction solid residue; (a) 400X magnification, (b) 1000X magnification.

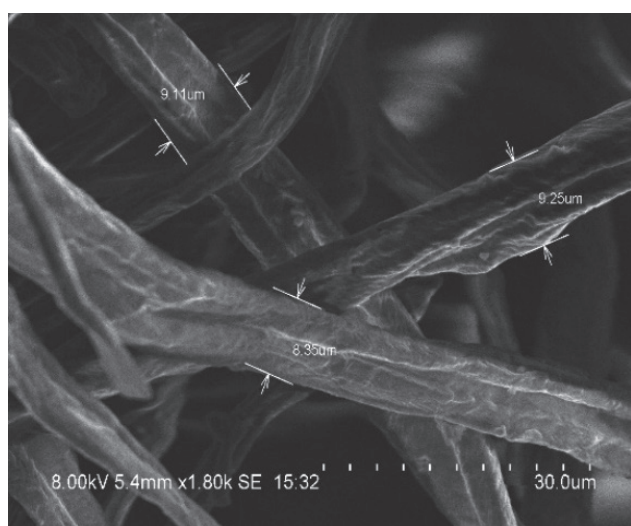

(a)

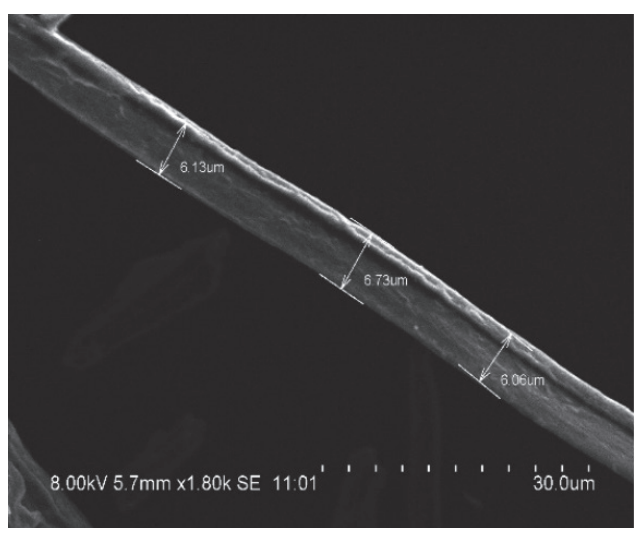

(b)

Figure 5. Scanning electron microscope (SEM) micrograph of the extracted cellulose;

(a) 1800X magnification, (b) 1800X magnification.

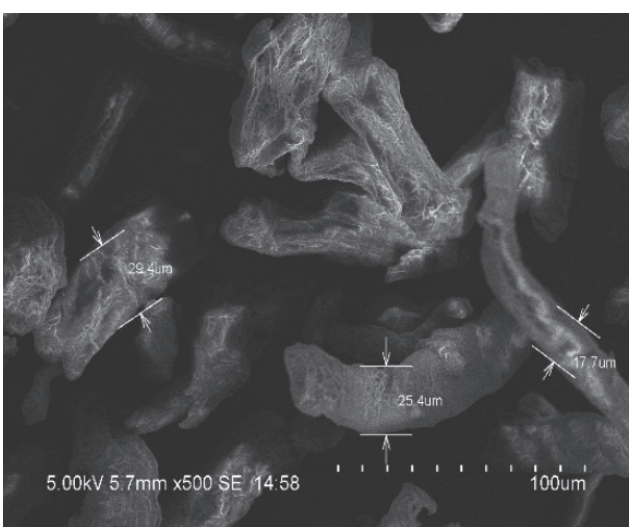

(a)

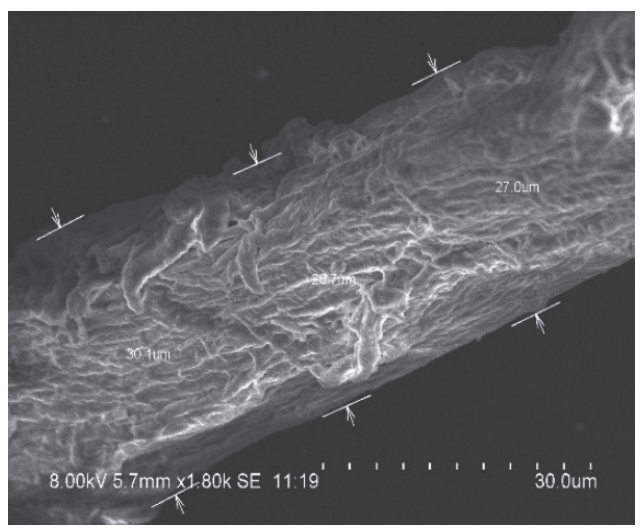

(b)

Figure 6. Scanning electron microscope (SEM) micrograph of the standard cellulose; (a) 500X magnification, (b) 1800X magnification.

Figure $4 a$ shows that the solid residue of OPEFB xylan extraction is a lignocellulosic composite with compact fibril packing, having average diameter of $93.07 \pm 2.78 \mu \mathrm{m}$, suggesting incomplete removal of lignin and hemicellulose (Megashah et al., 2018; Nazir et al., 2013). Complete microfibrillation with microfibrils in the fibre bundle with diameter of $6.29 \pm 0.17 \mu \mathrm{m}$ is observed in Figure $4 b$. The extraction of hemicellulose (xylan resource) from native OPEFB fibre via alkaline treatment generates solid residue consisting of cellulose, lignin while the remaining hemicellulose results in compact 
fibrillated structure. From Figure 5a, the microfibrils of the extracted cellulose have average diameter of $8.90 \pm 0.39 \mu \mathrm{m}$, indicating the disruption of lignocellulosic structure. The fibre bundles were separated into individual cellulose microfibres, indicating that lignin and hemicellulose were removed through bleaching (Megashah et al., 2018; Sofla et al., 2016; Zeng et al., 2014). As depicted in Figure $5 b$, there was an individual cellulose microfibre with a diameter of $6.31 \pm 0.30$. Figures $6 a$ and $6 b$ show incomplete microfibrillation as compared to solid residue and extracted cellulose morphologies due to the presence of non-fibrillated structure. There are uniform microdimensional crystal bundles and smooth surface, indicating that it was in the crystalline form. This supports the XRD results that standard cellulose has higher crystallinity index than extracted cellulose. The smooth surface indicates there is no inorganic materials or impurities on the standard cellulose.

\section{Elemental Analysis}

Chemical compositions analysis. As shown in Table 2 , oxygen $(\mathrm{O})$ was detected as the main element in both samples besides carbon (C) and hydrogen $(\mathrm{H})$. Nitrogen $(\mathrm{N})$ was also detected but the value was insignificant. No sulphur (S) was found in both samples. The $\mathrm{C}, \mathrm{H}, \mathrm{O}$, and $\mathrm{N}$ composition in the extracted cellulose was similar to standard cellulose.

Trace elements analysis. The existence of impurities in samples indicates the quality of the product. The quantity of trace elements and halogen content in both samples is tabulated in Table 3.

From the findings, no bromine was detected in both samples. The concentration of chlorine in the extracted cellulose $(0.21 \%)$ was comparable to the standard cellulose $(0.22 \%)$. It is deemed negligible as the amount is below $1.0 \%$. Fluorine (F) $(0.01 \%)$, iodine (I) $(0.13 \%)$, and S $(0.04 \%)$ were also detected but in insignificant quantity. Concentration of phosphorus $(\mathrm{P})$ was highest in both extracted and standard celluloses, at $1.20 \%$ and $1.40 \%$ respectively. $P$ comes from soil and fertiliser. Fertiliser is used in the oil palm plantation when the available $\mathrm{P}$ in the soil is less than $15 \mathrm{mg} \mathrm{kg}^{-1}$ (Sundram et al., 2019; Afandi et al., 2016; Goh and Rolf, 2003; Adiwiganda, 2002; Rankine and Fairhust, 1999). P is essential for plant growth and also important for root growth in the early growth stage of the plant. Therefore, the presence of $\mathrm{P}$ in the OPEFB-based cellulose is higher than other elements.

TABLE 2. CHEMICAL COMPOSITION OF THE EXTRACTED AND STANDARD CELLULOSE

\begin{tabular}{|c|c|c|}
\hline \multirow{2}{*}{ Components } & \multicolumn{2}{|c|}{ Chemical composition $(\%)$} \\
\hline & Extracted cellulose & Standard cellulose \\
\hline Carbon (C) & $39.58 \pm 0.11$ & $41.66 \pm 0.49$ \\
\hline Hydrogen $(\mathrm{H})$ & $6.01 \pm 0.09$ & $6.60 \pm 0.11$ \\
\hline Oxygen $(\mathrm{O})$ & $54.35 \pm 0.24$ & $51.73 \pm 0.60$ \\
\hline Nitrogen $(\mathrm{N})$ & $0.06 \pm 0.04$ & $0.01 \pm 0.00$ \\
\hline Sulphur (S) & Not detectable & Not detectable \\
\hline
\end{tabular}

Note: Data reported are the means of three replicate analyses of independent samples.

TABLE 3. CONTENTS OF TRACE ELEMENTS AND HALOGEN IN THE EXTRACTED AND STANDARD CELLULOSE

\begin{tabular}{lcc}
\hline \multirow{2}{*}{ Elements } & \multicolumn{2}{c}{ Concentration (\%) } \\
\cline { 2 - 3 } & Extracted cellulose & Standard cellulose \\
\hline Fluorine (F) & $0.01 \pm 0.0$ & $0.01 \pm 0.0$ \\
Chlorine (Cl) & $0.21 \pm 0.01$ & $0.22 \pm 0.01$ \\
Bromine (Br) & Not detectable & Not detectable \\
Iodine (I) & $0.13 \pm 0.01$ & $0.14 \pm 0.01$ \\
Sulphur (S) & $0.04 \pm 0.01$ & $0.07 \pm 0.01$ \\
Phosphorus (P) & $1.20 \pm 0.17$ & $1.40 \pm 0.01$ \\
\hline
\end{tabular}

Note: Data reported are the means of three replicate analyses of independent samples. 


\section{CONCLUSION}

Cellulose with $\alpha$-cellulose content and crystallinity index of $84.16 \pm 0.4 \%$ and $54.4 \%$, respectively was successfully recovered from the OPEFB-xylan extraction residue using green method of $20 \%$ formic acid and $5 \%$ hydrogen peroxide. The results from FTIR, TG and elemental analyses showed that the extracted cellulose has similar chemical properties and characteristics of standard cellulose. With the recovery of all OPEFB components, disposal issue can be solved, as well as creating value-added products from OPEFB-fibre.

\section{ACKNOWLEDGEMENT}

The authors would like to thank the DirectorGeneral of MPOB for permission to publish this article. They also wish to thank the Deputy Director-General (Research \& Development) and Director of Engineering and Processing Research Division, MPOB for their support.

\section{REFERENCES}

Adela, N B; Nasrin, A B; Loh, S K and Choo, Y M (2014). Bioethanol production by fermentation of oil palm empty fruit bunches pretreated with combined chemicals. Appl. Environ. Biol. Sci., 4: 234242.

Adiwiganda, R (2002). Defining the nutrient formulation and its minimum dosage of compound fertiliser based on the nutrient status of soil family for oil palm plantation in Indonesia. International Oil Palm Conference. Nusa Dua, Bali, 8-12 July, 2002. 24 pp.

Afandi, A M; Zulkifli, H; Khalid, H; Hasnol, O; Nur Zuhaili, H A Z A and Zuraidah, Y (2016). Oil palm fertiliser recommendation for Sabah soils. Oil Palm Bulletin No. 72: 1-24.

Alonso, J L; Domínguez, H; Garrote, G; Parajó, J C and Vázquez, M J (2003). Xylooligosaccharides: Properties and production technologies electron. J. Environ. Agric. Food Chem., 2(1): 230-232.

Bhatnagar, A and Sain, M (2005). Processing of cellulose nanofibre-reinforced composites. J. Reinf. Plast. Compos., 24: 1259-1268.

Brendel, O; Ianetta, P P M and Stewart, D (2000). A rapid and simple method to isolate pure alphacellulose. Phytochem. Anal., 11: 7-10.
Chang, S H (2014). An overview of empty fruit bunch from oil palm as feedstock for bio oil production. Biomass Bioenergy, 62: 174-181.

Ching, Y C and Ng, T S (2014). Effect of preparation conditions on cellulose from oil palm empty fruit bunch fibre. Bioresources, 9: 6373-6385.

Dhillon, GS; Kaur, S and Brar, S K (2013). Perspective of apple processing wastes as low-cost substrates for bioproduction of high value products: A review. Renew. Sustain. Energy Rev., 27: 789-805.

Fahma, F; Iwamoto, S; Hori, N; Iwata, T and Takemura, A (2010). Isolation, preparation and characterisation of nanofibers from oil palm empty fruit bunch (OPEFB). Cellulose, 17: 977-985.

Goh, J K and Rolf, H (2003). General oil palm nutrition. Oil Palm Management for Large and Sustainable Yields (Fairhust, T and Rolf, $\mathrm{H}$ eds.). p. 191-220.

Goldmann, W M; Ahola, J; Mikola, M and Tanskanen, J (2017). Formic acid aided hot water extraction of hemicellulose from European silver birch (Betula pendula) sawdust. Bioresour. Technol., 232: 176-182.

Gupta, P K; Agrawal, P and Hegde, P (2012). A review on xylooligosaccharides. Int. Res. J. Pharm., 3(8): 71-74.

Hook, B A; Halfar, J; Bollmann, J; Gedalof, Z; Rahman, M A; Reyes, J and Schulze, D J (2015). Extraction of $\alpha$-cellulose from mummified wood for stable isotopic analysis. Chemical Geology, 405: 19-27.

Jonoobi, M; Khazaeian, A; Tahir, P; Azry, S and Oksman, K (2011). Characteristics of cellulose nanofibres isolated from rubbwerwood and empty fruit bunches of oil palm using chemo-mechanical process. Cellulose, 18: 1085-1095.

Khalil, H P S A; Ismail, H; Rozman, H D and Ahmad, M N (2001). The effect of acetylation on interfacial shear strength between plant fibres and various matrices. Eur. Polym. J., 37: 1037-1045.

Khalil, H P S A; Siti Alwani, M; Ridzuan, R; Kamarudin, K and Khairul, A (2008). Chemical composition, morphology characteristics, and cell wall structure of Malaysian oil palm fibres. Polm. Plast. Technol. Eng., 47: 273-280.

Kushairi, A; Ong-Abdullah, $\mathrm{M}$; Balu, N; Hishamuddin, E; Izuddin, Z B; Razmah, G; 
Subramaniam, V; Sundram, S and Parveez, G KA(2019). Oil palm economic performance in Malaysia and R\&D progress in 2018. J. Oil Palm Res. Vol. 31(2): 165-194.

Law, K N; Daud, W R W and Ghazali, A (2007). Morphological and chemical nature of fibre strands of oil palm empty-fruit-bunch (OPEFB). Bioresources, 2: 351-362.

Leavitt, S W and Danzer, S R (1993). Method for batch processing small wood samples to holocellulose for stable-carbon isotope analysis. Anal. Chem., 65: 87-89.

Li, B; Xu, W; Kronlund, D; Määttänen, A; Liu, J; Smått, J H and Xu, C (2015). Cellulose nanocyrstals prepared via formic acid hydrolysis followed by TEMPO-mediated oxidation. Carbohydr. Polym., 133: 605-612.

Lindman, B; Karlsöm, G and Stigsson, L (2010). On the mechanism of dissolution of cellulose. J. Mol. Liq., 156: 76-81.

Loader, N J; Robertson, I; Barker, A C; Switsur, V R and Waterhouse, J S (1997). An improved technique for the batch processing of small wholewood samples to $\alpha$-cellulose. Chem. Geol., 136: 313-317.

Manderson, K; Pinart, M; Tuohy, K M; Grace, W E; Hotchkiss, A T; Widmer, W; Yadhav, M P; Gibson, G S and Rastall, R A (2005). In vitro determination of properties of oligosaccharides derived from an orange juice manufacturing by-product stream. Appl. Environ. Microbial., 71(12): 8383-8389.

Mansor, AM; Lim, JS; Ani, F N; Hashim, Hand Ho, W $S$ (2019). Characteristics of cellulose, hemicellulose and lignin of MD2 pineapple biomass. Chemical Engineering Transactions, 72: 79-84.

Marzialetti, T; Miller, S J; Jones, C W and Agrawal, P K (2011). Switchgrass pretreatment and hydrolysis using low concentrations of formic acid. J. Chem. Technol. Biotechnol., 86: 706-713.

McKendry, P (2002). Energy production from biomass (Part 1): Overview of biomass. Bioresource Technology, 83(1): 37-46.

Megashah, L N; Ariffin, H; Zakaria, M R and Hassan, M A (2018). Properties of cellulose extract from different types of oil palm biomass. IOP Conf. Ser.: Mater. Sci. Eng., DOI: 10.1088/1757899X/368/1/012049.

Moran, J I; Alvarez, V A; Cyras, V P and Vazquez, A (2008). Extraction of cellulose and preparation of nanocellulose from sisal fibres. Cellulose, 15: 149-159.
Moure, A; Gullon, P; Domínguez, H and Parajo, J C (2006). Advances in the manufacture, purification and applications of xylo-oligosaccharides as food additives and nutraceuticals. Proc. Biochem., 41(9): 1913-1923.

Nascimento, P; Mariam, R; Carvalho, G; Celso, $R$ and Cid, G (2015). Nanocellulose produced from rice hulls and its effect on the properties of biodegradable starch film. Materials Research, 19: 1-18.

Nawirska, A and Kwasniewska, M (2005). Dietary fibre fractions from fruit and vegetable processing waste. Food Chem., 91: 221-225.

Nazir, M S; Wahjoedi, B A; Yussof, A W and Abdullah, M A (2013). Eco-friendly extraction and characterisation of cellulose from oil palm empty fruit bunches. BioResources, 8: 2161-2172.

Nazir, M S; Wahjoedi, B A; Yussof, A W and Abdullah, M A (2012). Green extraction and characterisation of cellulose fibres from oil palm empty fruit bunch. $2^{\text {nd }}$ International Conference on Process Engineering and Advanced Materials (ICPEAM2012) under World Engineering, Science \& Technology Congress (ESTCON2012). Kuala Lumpur.

Noorshamsiana, A W; Astimar, A A; Nor Faizah, J and Mohamadiah, B (2015). Enzymatic production of xylo-oligosaccharides from fibers of empty fruit bunch. MPOB Information Series No. 701: 2 pp.

Norzita, N and Lani, N S (2014). Extraction and characterisation of cellulose from empty fruit bunch (EFB) fibre. J. Teknologi, 68: 35-39.

Parajó, J C; Garrote, G; Cruz, J M and Dominguez, H (2004). Production of xylooligosaccharides by autohydrolysis of lignocellulosic materials. Trends in Food Science and Technology, 15(3-4): 115-120.

Patterson, A L (1939). The Scherrer formula for X-ray particle size determination. Physical Review, 56: 978-982.

Poletto, M; Ornaghi Júnior, H L and Zattera, A J (2014). Native cellulose: Structure, characterisation and thermal properties. Materials, 7: 6105-6119.

Rankine, I and Fairhust, T H (1999). Management of phosphorus, potassium and magnesium in mature oil palm. Better Crops International, 13: 10-15.

Rosnah, M S; Astimar, A A; Wan Hasamudin, W H and Gapor, M T (2009). Solid-state characteristics of microcrystalline cellulose from oil palm empty fruit bunch fibre. J. Oil Palm Res. Vol. 21: 613620. 
Seema, P and Arun, G (2011). Functional oligosaccharides: Production, properties and applications. World J. Microbiol Biotechnol., 27: 11191128.

Segal, L; Creely, J J; Martin, A E and Conrad, C M (1959). An empirical method for estimating the degree of crystallinity of native cellulose using the X-ray diffractometer. Textile Research J., 29: 786-794.

Simone, M L R; Rehman, N; De Miranda, M I G; Nachtigall, S M B and Bica, C I D (2012). Chlorinefree extraction of cellulose from rice husk and whisker isolation. Carbohydr. Polym., 87: 1131-1138.

Sofla, M R K; Brown, R J; Tsuzuki, T and Rainey, T J (2016). A comparison of cellulose nanocrystals and cellulose nanofibres extracted from bagasse using acid and ball milling methods. Advances in Natural Sciences: Nanoscience and Nanotechnology, 7: 1-9.

Sun, R; Fang, J M; Mott, L and Bolton, J (1999). Extraction and characterisation of hemicellulose and cellulose from oil palm trunk and empty fruit bunch fibres. J. Wood Chem. Technol., 19: 167-185.

Sundram, S; Angel, L P L and Sirajuddin, S A (2019). Integrated balanced fertiliser management in soil health rejuvenation for a sustainable oil palm cultivation: A review. J. Oil Palm Res. Vol. 31(3): 348-363.

Szymańska-Chargot, M; Chylińska, M; Gdula, K; Koziol, A and Zolunek, A (2017). Isolation and characterisation of cellulose from different fruit and vegetable pomaces. Polymers, 9: 495-511.

Wanrosli, W D; Zainuddin, Z and Lee, L K (2004). Influence of pulping variables on the properties of Elaeis guineensis soda pulp as evaluated by response surface methodology. J. Wood Chem. Technol., 38: 191-205.

Wise, L E; Murphy, M and Addieco, A A D (1946). Chlorite holocellulose, its fractionation and bearing on summative wood analysis and on studies on the hemicelluloses. Paper Trade J., 122: 35-43.

Zakaria, M R; Hirata, S and Hassan, M A (2015). Hydrothermal pretreatment enhanced enzymatic hydrolysis and glucose production from oil palm biomass. Bioresour. Technol., 176: 142-148.

Zeng, Y; Zhao, S; Yang, S and Ding, S (2014). Lignin plays a negative role in the biochemical process for producing lignocellulosic biofuels. Curr. Opin. Biotechnol., 27: 38-45. 